\title{
From Household Size to the Life Course
}

\author{
Some Observations on Recent Trends \\ in Family History
}

\section{MARIS A. VINOVSKIS \\ University of Michigan}

After many years of neglect, the field of family history has become, during the last 15 years, one of the fastest growing areas of historical research. The quantity and quality of research on the history of the family has greatly increased and improved. Historians are now investigating topics such as childbearing, childrearing, labor-force participation, aging, and death within the context of family life in the past. In fact, the field has become so large and so diverse that it is no longer possible to attempt a comprehensive survey of the field in a short essay.

Rather than trying to summarize or even comment on the wide variety of issues being raised in the study of family history today, this essay will focus on the efforts during the past 10 years to develop a comprehensive framework for the analysis of family history. Particular attention will be paid to four alternative approaches for studying the 
family - the analysis of household size and composition, the study of generations, the use of a family-cycle model, and the development of a life-course perspective. By concentrating on these four approaches, it will be possible to raise some of the most important, current conceptual and methodological issues in the field of family history. Though major topics such as the analysis of past kinship patterns can only be mentioned in passing, this does not imply that these substantive issues deserve less attention or emphasis than the effort to develop a better conceptual framework for the study of family history. ${ }^{1}$

Despite the popularity of studying contemporary families during the 1940 s and 1950 s, social scientists did not investigate family life in the past. Instead, most anthropologists and sociologists were content to use the findings from analyses of contemporary primitive families to make inferences about the nature of the preindustrial Western family. These social scientists assumed preindustrial families were larger and more complex than those today. In fact, they argued that ind ustrialization led to the shift from the extended family to the nuclear family.

During the 1960s scholars from a variety of disciplines began to reexamine the historical family. Rather than relying only on the scattered literary references to family life, they utilized quantitative data from the censuses and vital records in an effort to recreate family life in the past. The direction of these efforts took quite different, though related, paths. On the one hand, historical demographers such as Louis Henry (1956) and E. A. Wrigley (1969) used parish records to study the demographic characteristics of family life. Using the technique of family reconstitution, they estimated rates of marriages, births, and deaths for past societies. Though they were interested in many aspects of family life, they were not particularly concerned with the size or composition of families at any given time. ${ }^{2}$ On the other hand, a group of family historians, led by Peter Laslett (1972a) and the Cambridge Group for the History of Population and Social Structure, used the surviving nominal censuses to study family size and composition in the past. During the late 1960 s and early 1970s, it was the latter group that became the center of a far-reaching debate on the nature of the preindustrial family.

Laslett investigated the size and structure of English households in 100 parishes from 1574 to 1821 (1972b). He found that most households were nuclear rather than extended and that the size of these households remained relatively constant over time. Thus, Laslett argued that the notion that industrialization created the nuclear household in England 
is a myth since the proportion of extended households was never very large in preindustrial England.

Under the guidance and encouragement of Laslett and the Cambridge Group, scholars studied the mean household size and the proportion of families that were nuclear in several different cultures and time periods (Laslett, 1972a). With a few notable exceptions, these studies confirmed that the mean household size was relatively constant over time and across cultures, and that most households at any given point in time were nuclear. To some extent, studies of family structure using this framework of analysis dominated the field in the late 1960s and early 1970 s as scholars in different countries coordinated their research in an effort to produce a comparative history of household size and structure.

The study of mean household size did not go unchallenged as several scholars questioned the meaning and value of this measure. Some raised the objection that Laslett's definition of household was too narrow because it attempted to impose an English model of the family on cultures for which this framework was inappropriate (Berkner, 1975). Laslett's operational definition of the household was even challenged by those working with English-speaking cultures because it excluded boarders and lodgers and failed to consider the importance of kin living outside the household (Hareven, 1974; Katz, 1975). Furthermore, just as Laslett and his colleagues were trying to develop a definition of households that would be meaningful for different cultures and time periods, other social scientists studying the family were moving toward a more flexible definition of the family that took into consideration the variations in the values about and the behavior of families in different cultures (Skolnick, 1975). Thus, while one of the main appeals of the Laslett approach was that it provided a definition of the household that could be used as the basis of a comparative approach to fa mily life, critics have questioned the utility of his particular delineation of the household and of its applicability to other cultures.

The most damaging and sharpest criticism of Laslett's approach was that the study of the family should be based on a developmental rather than a static perspective. Instead of calculating the average size of households or the proportion that were nuclear at any given point in time, we should estimate the size and composition of families as they developed over time. Thus, Lutz Berkner (1975) argues that even if extended families were only a small proportion of households at any given time, a much larger percentage of households might have been extended at some point in their development. ${ }^{3}$ In fact, as Marion Levy 
(1965) has pointed out, demographic considerations alone would severely limit the proportion of households that could be extended at any one time since few individuals in the past lived long enough to be in the same household with their married children and grandchildren.

The debate on the usefulness of studying mean household size or the proportion of families that are nuclear has not ended. To be sure, Laslett has admitted some of the limitations of his approach. For example, in his analysis of the type of households in which young children were raised, he (1977) acknowledges the real limitations of focusing only on the members within the household itself and of neglecting to investigate the impact of beliefs and customs:

The disposition of the knot of persons co-residing with a child under five years old can always be recovered from a good listing of inhabitants surviving from the past, one which specifies ages and divides one familial group from another. But persons present within the household make up only a proportion of the influences from kin and from others close to the child. There is the affective quality of family life to be taken into account, as well as the impact of beliefs, customs, norms about child rearing and desirable behavior for the young. Neither these, nor the geographic propinquity of kin folks other than the immediate family, nor the extent to which they would visit the household in question can be inferred from our evidence.

Yet Laslett and his associates continue to advocate measuring mean household size and determining the proportion of households that were nuclear. But the proponents of this approach are now clearly and properly on the defensive as they are challenged to demonstrate the value of their particular measures-a serious problem for them since the use of mean household size has not been adequately grounded on any concept or theory of family behavior or societal development.

Sociologists of the family also have been searching for an appropriate conceptual framework for analyzing family development. A variety of different approaches have been suggested and tested-some of which have been borrowed by historians of the family. One way of studying change over time in the characteristics of families is to trace differences between generations. Thus, Reuben Hill and his associates (1970) studied changes in long-term financial planning and consumption patterns among families from three different generations. The advantage of a generational approach is that it permits a direct comparison of parents with their children or with their own parents - a very useful perspective if we are interested in the transmission of values and goods across generations. Unfortunately, the 
generational approach is often limited because the same generation may contain members from such different age cohorts that the members of the same generation may have grown up in such different time periods that they are as different from each other as they are from another generation. Thus, the middle generation in Hill's (1970) study consists of parental couples who were married in the 1920s or 1930stwo very different time periods which undoubtedly produced very different life experiences for members of that middle generation ${ }^{4}$

Family historians have also used a generational approach-often without considering the implications of using this framework. Philip Greven's (1970) analysis of the first settlers of Andover, Massachusetts and their descendents was organized along generational lines (the first settlers were designated as the first generation, their children became the second generation, and so on). His focus was on the problem of inheritance and how the transmission of property across generations affected the way in which fathers dealt with their children. By the fourth generation in Andover, significant changes had occurred in the demographic experiences of that group as well as their relationship to their fathers (Greven, 1970: 272).

\footnotetext{
By the time the fourth generation began to reach maturity during the middle decades of the century, much had changed. Not only were their lives cut short more often than in past generations, but they also reached maturity sooner, married younger, established their independence more effectively and earlier in life, and departed from the community with even greater frequency than in earlier generations. The ties binding men to their parents were loosening.
}

Though most of Greven's data and analysis were organized along these generational lines, he did not consider whether the use of generations was a meaningful way of ordering his data. ${ }^{5}$ For example, he should have checked whether the use of generations confused the actual experiences of different age cohorts as it did in Hill's (1970) analysis of Minnesota families. Greven does not discuss this problem and did not provide data on the age distribution of the different generations over time. We can examine the usefulness of a generational approach for his analysis by estimating from his charts the number of marriages in consecutive five-year intervals for the second, third, and fourth generations (see Figure 1).

Plotting the number of marriages for each generation by five-year intervals reveals the weakness of Greven's generational approach. Some of the third-generation marriages overlap with those of the second 


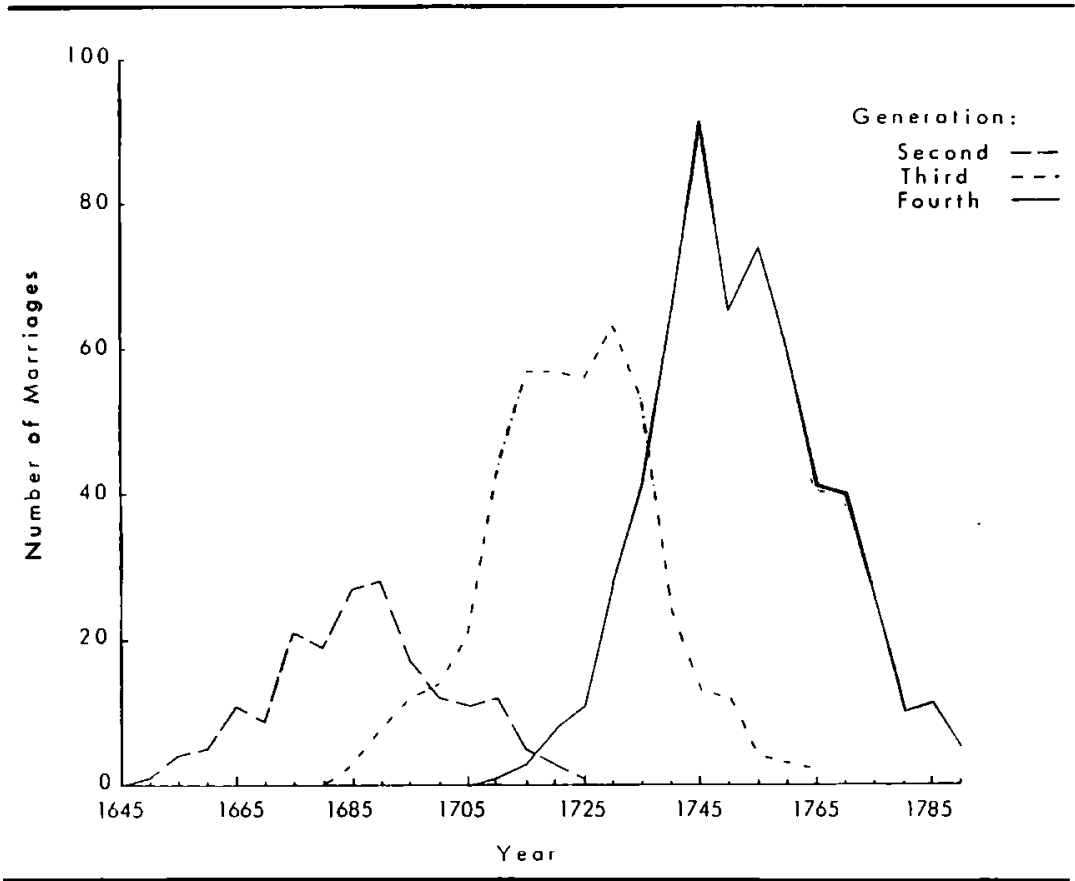

Figure 1. Number of Marriages in Five-Yeer Intervals in Andover. Massachusetts, $1645-49$ to $1785-89$.

generation while some of the others of the third generation overlap with those from the fourth generation. Furthermore, the marriages for each of the second, third, and fourth generations span an 80-year period. In other words, members belonging to any one of these generations include individuals of quite varying ages so that it is not meaningful to compare demographic and socioeconomic characteristics across generations because we cannot be certain that the variations are due to being a member of a different generation or simply growing up during a different time period. ${ }^{6}$

The use of generations in historical analysis can be useful in certain situations-particularly when one is studying the transmission of property across generations as Greven did. The problem arises, however, when the members of the generations are so spread across broad time periods, as were the descendents of the first settlers in Andover, that generational comparisons become at least ambiguous if 
not misleading. In this situation, Greven should have either abandoned his generational approach entirely by organizing his data by birth cohorts or at least modified it by further subdividing his third and fourth generations according to their date of birth. Otherwise, it is impossible to separate analytically the effect of being a member of a particular generation from the effect of growing up in a different time period with very different economic opportunities and constraints.

The analysis of the average size of households and the proportion that are nuclear at a particular point in time has been strongly criticized for failing to recognize the importance of changes in family life as new members are added or old ones depart. Similarly, though the generational approach provides a framework for analyzing the transmission of values or goods between parents and their children (or simply for comparing the experiences of children to those of their parents), it does not attempt to identify what particular aspects of family life should be studied or how they might be investigated. There have been efforts, however, to create a more developmental perspective for studying families as they evolve from their initial formation to their final dissolution. One description of the developmental approach to family life characterizes it as:

Family development views the nuclear family as a small group system, intricately organized internally into paired positions of husband-wife, wife-mother, son-brother and daughter-sister. Norms prescribing the appropriate role behavior of each of these positions specify how reciprocal relations are to be maintained as well as how role behavior may change with changing ages of the occupants of these positions. This intimate small group has a predictable natural history designated by stages beginning with simple husband-wife pair, and becoming more and more complex with each additional position that is activated, then becoming less complex as members are launched into jobs and marriage and the group contracts in size to the husband-wife pair once again. As the age composition of the family changes, so do the expectations for the occupants of the positions in the family change, and so does the quality of interaction between family members [Hill, 1964: 188].

The family-developmental approach is a very general and flexible perspective that emphasizes changes in family size, composition, and social roles over time. Most sociologists of the family using this perspective, however, have employed a more systematic and more narrow version of it by delineating definite stages of family life and organizing them into a sequential pattern called the family cycle. The 
TABLE 1

\section{Evelyn Duvall's Eight-Stage Model of the Family Cycle}

\begin{tabular}{ll}
\hline Stage I & Beginning Families (married couple without chirdren) \\
Stage II & Childbearing Families (oldest child, birth to 30 months) \\
Stage III & Families with Preschool Children (oldest child $21 / 2$ to \\
& 6 years) \\
Stage IV & Families wich School Children (oldest child 6 to 13 years) \\
Stage V & Families with Teenagers (oldest child 13 to 20 years) \\
Stage VI & Families as launching Centers (first child gone to last \\
& child's leaving home) \\
Stage VII & Families in Middle Years (empty nest to retirement) \\
Stage VIII & Aging Families (retirement to death of one or both spouses) \\
\hline
\end{tabular}

a. Source: Duvall (1967)

family-cycle approach identifies variations in family life largely on the basis of changes in family size due to the arrival and departure of children. There are several different ways in which the family cycle has been defined. Some scholars have simply divided the family cycle into two categories - a period of expansion and one of contraction. Probably the most extensively used model is the one developed by Evelyn Duvall (1967) which has eight stages (see Table 1). Duvall's eight-stage model is based on shifts in the size and composition of the family as well as changes in social roles within the family. To operationalize the latter, she considers each instance of the oldest child shifting from one significant age-category to another as the beginning of a new stage. The assumption behind her model is that changes in the experiences of the oldest child subject the entire family to new and different problems to which its members must adjust their behavior and expectations.

The Duvall family-cycle model has been criticized for masking significant changes in family life during the middle stages. As a result, Roy Rodgers (1962) modified her scheme by taking into consideration not only when the oldest child moves from one significant age category to the next, but also when the youngest child makes those transitions. Using this refinement, Rodgers developed a 24 stage family-cycle 
model which recognizes more changes in family life, but is much more cumbersome to operationalize-especially with small samples. Consequently, most sociologists have continued to use Duvall's eight-stage model even though it neglects some of the interesting variations in the middle stages.

As a typology of family life, the stages of the family cycle can suggest interesting and useful areas for analyzing family development. Researchers also find it a convenient organizing scheme for gathering or ordering their longitudinal data on the family. Particularly valuable in the family-cycle approach is the emphasis on the importance of compositional and size effects on family life-an area that most historians have neglected. The way in which most historians have treated the economics of family life illustrates their lack of attention to the importance of household size and composition in affecting the economic wellbeing of the family.

Almost all of the studies of American-family life based on the nineteenth-century censuses have used the occupation of the head of the family as the index of its status and well-being without considering the number of wage-earners and consumers in that family. ${ }^{7}$ Thus, a family composed of a carpenter, his wife, and their two children are treated as equivalent to a family headed by a carpenter, his working wife, and no children.

Though the occupation of the head of the household is a useful and important indication of the economic well-being of the family, it is not the only information we would like to have. Ideally, we would have some measure of the income generated by the family as well as the amount of goods consumed by that family. While such data are available for contemporary studies of the family, they are not available from the nineteenth-century censuses. ${ }^{8}$ It is possible, however, to go beyond reliance only on the occupation of the head of the household by calculating an index of the number of individuals who are employed as well as the number of consumers in that household. Such an index can provide a crude measure of the relative differences between households in their ability to support the economic needs of their members (especially if we control for the differences in the occupation of the heads of households).

Recently, an effort has been made to develop an index of the relative well-being of households by taking into consideration the number of consumers and producers in that household (Kaestle and 
Vinovskis, forthcoming, Mason et al., forthcoming). Since the earning and consuming ability of individuals vary by age and sex, these studies adjusted the number of consumers and producers in each household by employing a set of weights taking these factors into consideration (e.g., it was assumed that a twelve year-old boy consumed only three-fourths as much as an adult and could only earn about three-tenths as much as an adult male). ${ }^{9}$ This work/consuming index is therefore a crude measure of the number of working units in each household divided by the number of consuming units. Though this index does not fully capture the individual family variations in income adequacy, it at least provides a beginning toward the measurement of a family's economic situation rather than just an individual's situation.

This work/consumption index was used in two different studiesone on the pattern of school attendance (Kaestle and Vinovskis, forthcoming) and another on the participation of women in the labor force (Mason et al., forthcoming). In both of these analyses, the work/ consumption index was used in conjunction with the occupation of the head of the household to explain some behavior such as school attendance or labor-force participation. Though it is likely that this particular index may be modified as researchers experiment with different weighting schemes, so far it has proven to be useful both conceptually and empirically in these two investigations.

The family-cycle approach is useful for suggesting areas of family life that may need additional research and for emphasizing the importance of changes in family size and composition. Nevertheless, it is not a satisfactory framework for studying family life. Variations in a family-cycle model are partly due to changes in the size of the family, partly the result of changes in the age composition of the family, and partly the consequence of changes in the social roles of family members. The family-cycle approach does not attempt to separate out the significance of these different, though related, factors on family life. Furthermore, the family-cycle approach often does not make full use of the available information on members of that family. Information on the work experiences of the parents are not fully incorporated in these models. Finally, though the family-cycle model was created to deal with changes in family life over time, it does not pay very much attention to the timing and sequencing of events in the lives of the family members. Thus, although the family-cycle approach is an improvement on the static typologies of family life used by previous 
family sociologists, it is still too narrowly and rigidly conceived to make full use of the available information to develop a really dynamic and interactive model of family-life processes.

Though historians are just now discovering and advocating the use of the family-cycle model, this approach does not appear to be particularly useful for historical analysis. Not only is a family-cycle approach inherently limited by its emphasis on stages, it is also inappropriate for historical analysis because it is based on a model of the modern family which is not suited for research on the family in the past. For example, most family-cycle models rely very heavily on the changes introduced by the addition or departure of children from the family. In the past, however, children entered or left the home over a much longer time span so that these events often overlapped and therefore could not be as easily described by any sequential typology of stages. Furthermore, the family-cycle approach focuses only on family members in creating the different stages. In the past, there was less of a distinction between family and nonfamily members in households than today. As a result, most existing family-cycle models are inadequate for historical analysis since they do not take into consideration the presence and the impact of boarders and lodgers.

It may be possible, of course, to construct an alternative family-cycle model that takes into consideration the differences in family life in the past. In fact, some historians (Hareven, 1974: 326-327) have called for an historical study of the family cycle:

The cycle approach to the historical study of the family does not merely substitute a time unit of analysis for the current structural unit. Historians who will substitute longitudinal tracing or record linkage for cross-sectional analysis, without developing a conceptual scheme, will be moving from one mechanical category to another. Family research in the next few years will have to determine what type of family cycles existed and what the significant stages of transition were. Historians of the life cycle (childhood, adolescence, youth) have already demonstrated the fact that stages of psycho-biological development are socially defined, and that it would be impossible, therefore to rely on universal stages. Similarly, stages in the family cycle are not governed simply by biological age grades. In their analysis of contemporary groups, family sociologists are grappling with the classifications of stages of the family cycle. Historians will not only need to define such stages for past societies, but to interpret their relationship in the historical contexts.

Historians may be able to create a family-cycle model that is more appropriate for historical analysis, but any family-cycle model will 
still be too narrowly conceived to provide an adequate framework for studying family life. If one tried to develop a family-cycle model that took into consideration the major variations in family life in the past as well as today, it would require even more stages than Rodgers' (1962) proposed 24-stage model. Considering the difficulties involved in developing an adequate family-cycle model for the past, it is not surprising that historians have not yet operationalized any suitable comprehensive model. Rather than trying to develop an overall model of the family cycle, historians should study either a particular aspect of family life, such as childbearing, or a series of family events, such as the transition of children from school to work, using a more flexible and more comprehensive approach-life-course analysis. 10

The life-course approach to the study of family development has become increasingly popular among scholars from many different disciplines. One of its ablest proponents is Glen Elder (1974; 1975), a sociologist who studied the effects of the Depression of the 1930s on children growing up during those years. Elder emphasizes the importance of studying the relationship between family events and historical events in analyzing the life-course experiences of individuals and their families.

The life-course approach draws very heavily upon the concept of aging as developed by demographers (Ryder, 1965) and sociologists (Riley et al., 1972). The age of individuals reflects at least three different aspects of their lives - their approximate stage of biological development, their age-related social roles, and their historical position. Drawing on this perspective as well as the Chicago School of Sociology tradition of studying life histories, Elder advocates the use of a life-course perspective to analyze family life in the past. Though the lifecourse approach defies any simple definition, Elder (forthcoming) summarizes it as:

The life course refers to pathways through the age-differentiated life span, to social patterns in the timing. duration, spacing, and order of events; the timing of an event may be as consequential for life experience as whether the event occurs and the degree or type of change. Age differentiation is manifested in expectations and options that impinge on decision processes and the course of events that give shape to life stages, transitions, and turning points. Such differentiation is based in part on the social meanings of age and the biological facts of birth, sexual maturity, and death. These meanings have varied through social history and across cultures at points in time, as documented by evidence on socially recognized age categories, grades, and classes. ... Over the life course, age differentiation also 
occurs through the interplay of demographic and economic processes, as in the relation between economic swings and the time of family events. Sociocultural, demographic, and material factors are essential elements in a theory of life course variation.

Not only have sociologists of the family used a life-course approach, but life-span psychologists and social demographers have found it a useful framework. Though historians have been late-comers to this perspective, some of them are now using it to study family life in the past. This involvement of historians is a healthy development because the life-course perspective is better suited to study the dynamics of family life than either a household-size and composition approach or a family-cycle framework-especially since the life-course approach is more sensitive to the shifts in the meaning of social roles over time and is particularly concerned with the interaction of family events and historical changes. In addition, since the life-course approach places such emphasis on the meaning of social roles in the past and of the historical context of an individual's experiences, the involvement of historians is essential in the development and use of a life-course perspective.

The life-course approach has much to recommend it. One of its drawbacks, however, is that the type and amount of longitudinal data needed are usually unavailable. There are, of course, some collections of twentieth-century data that could be used that have been overlooked by historians. Social scientists in the early twentieth century began panel studies of individuals which could be used to reconstruct familylife patterns. " Elder's (1974) analysis of children during the Depression is based on Herbert Stolz and Harold E. Jones's study of adolescents in Oakland in the 1930s and a follow-up study of the same persons during the 1960s. Historians should build on these earlier panel studies-even if it sometimes means that the subjects will have to be traced and retested today. 12

Though drawing on the early longitudinal studies is an effective way of studying the twentieth-century family, it also poses several methodological problems. Many of the panel studies begun in the 1920 s and 1930s were based on very small samples which were unrepresentative to begin with and became more so over time due to attrition in the sample. Since most of these studies were done without any clear hypotheses, the tests used and the data collected are not ideal for the needs of family historians today (Modell, 1975; Wall and Williams, 
1970). Nevertheless, many of these early longitudinal studies are useful for historical analyses as long as one is aware of their methodological shortcomings. Furthermore, most of the post-World War II panel studies are based on much larger samples, and are more carefully designed so that they are better than the earlier ones.

Very few panel studies were undertaken in the past, and given the high cost of such efforts, it is unlikely that many more will be initiated in the near future. As a result, even historians of the twentieth-century family will have to turn to alternative sources of data. One possible avenue is the use of retrospective-oral-histories. Sociologists and psychologists have made effective use of retrospective surveys to analyze the life course, and have dealt with the methodological problems such as the inaccurate recall of past events.

Oral history is now becoming very popular among historians and the general public-especially as we try to recreate the lives of ordinary people or to discover our own roots. Some family historians are using oral histories either as their main source of information or as a supplement to their other sources such as vital records and census data. Unfortunately, most studies utilizing oral histories have not been concerned with the methodological problems involved in such an effort. Problems of the accuracy of recalling past events or the selectivity introduced by the subjects we can locate for interviews have been largely ignored. Oral histories are unquestionably an excellent source of information about family life in the past, but their use must be guided by more rigorous methodological standards than we have seen in most such projects so far.

The reliance only on data from panel studies or retrospective surveys would restrict the analysis of family life to a relatively small proportion of the population and to the twentieth century. Consequently, family historians need to explore alternative sources of longitudinal data such as government pension records, insurance company files, and factory employment records. ${ }^{13}$

An alternative to longitudinal data for life-course analysis is to use cross-sectional data to make inferences about life-course processes in the past. The most widely available and used source of information on the American family of earlier periods are the manuscript federal censuses. Starting in 1850, the federal censuses collected their information in terms of individuals as well as households. As a result, it is possible to calculate age-specific rates for the socio-economic 
TABLE 2

Death Rates for All Forms of Tuberculosis for Massachusetts Males 1880 to 1930 (rates per 100,000 population)

\begin{tabular}{|c|c|c|c|c|c|c|}
\hline Age & 1880 & 1890 & 1900 & 1910 & 1920 & 1930 \\
\hline $0-4$ & 760 & 578 & 309 & 209 & 108 & 41 \\
\hline $5-9$ & 43 & 49 & 31 & 21 & 24 & 11 \\
\hline $10-19$ & 126 & 115 & 90 & 63 & 49 & 21 \\
\hline $20-29$ & 444 & 361 & 288 & 207 & 149 & 81 \\
\hline $30-39$ & 378 & 368 & 296 & 253 & 164 & 115 \\
\hline $40-49$ & 364 & 336 & 253 & 253 & 175 & 118 \\
\hline $50-59$ & 366 & 325 & 267 & 252 & 171 & 127 \\
\hline $60-69$ & 475 & 346 & 304 & 246 & 172 & 95 \\
\hline and over & 672 & 396 & 343 & 163 & 127 & 95 \\
\hline
\end{tabular}

SOURCE: Frost (1940)

characteristics of that population, and to use those rates to estimate the life-course pattern of individuals and their families. Most of the current work on the history of the family in the United States is based on such estimates from the censuses, and this approach will become even more common as family historians shift from a focus on household size and composition to life-course analysis.

Family historians are increasingly employing the manuscript censuses to reconstruct the pattern of family life in the past, but many of them are not aware of the implicit assumptions of their procedures. ${ }^{14}$ For example, there are often major differences between estimates based on cross-sectional data from only one time period and those based on a synthetic cohort constructed from a series of crosssectional censuses. We can illustrate this distinction by using the agespecific tuberculosis rates for Massachusetts males from 1880 to 1930 (Frost, 1940) [see Table 2]. The age-specific death rates for each time period are given in the columns labelled $1880,1890, \ldots 1930$. We can 


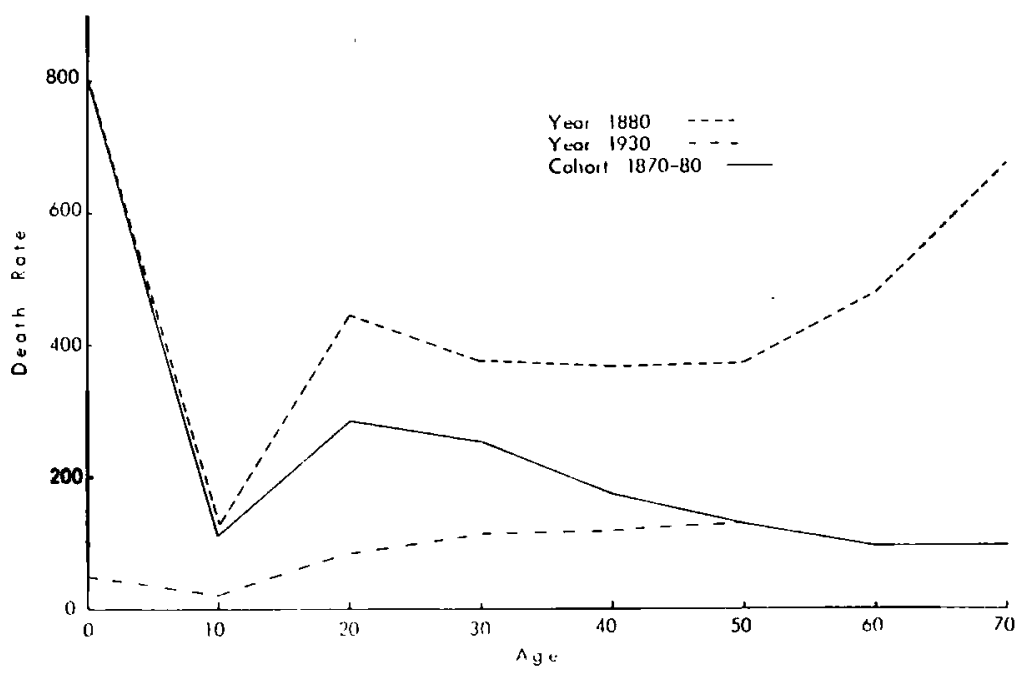

Figure 2. Comparison of Cross-sectional and Cohort Estimates of Tuberculosis Death Rates for Massachusetts Males, 1880-1930.

trace the experiences of a particular birth cohort by following their age-specific death rates at 10 -year intervals. For example, for the birth cohort of 1870-1880, their age-specific death rates were 115 for ages 10-19, 288 for ages 20-29, and 253 for ages 30-39.

We can graph the differences between estimates of mortality from the cross-sectional data at one point in time and those based on the construction of a synthetic cohort. If we estimated the mortality of the birth cohort of 1870-1880 using only the age-specific death rates for 1880 , we would greatly overestimate the extent of their mortality from tuberculosis-especially in their later years. On the other hand, if we estimated the mortality of the same cohort using only the agespecific death rates for 1930 , we would greatly underestimate the extent of their mortality from tuberculosis-particularly in their early years. Whenever there are rapid changes in age-specific rates over time, as in the case of tuberculosis death rates for Massachusetts males, any estimates based on cross-sectional data from only one point in time are very likely to misrepresent the actual experiences of a given cohort (though this is precisely the type of inferences that most family historians using census data have made). Instead, we should try to obtain 
age-specific data from several points in time to construct a synthetic cohort which will provide us with a better estimate of the actual life experiences of those individuals.

The use of cross-sectional census data from several different time periods to estimate the life experiences of any particular cohort also assumes that we are dealing with the same population (i.e., one that has not been substantially altered by in- or outmigration). This is rarely the case since most family historians study a small geographic areausually only a single urban community. ${ }^{15}$ Consequently, they (Modell et al., 1976: 10) have been forced to assume, implicitly or explicitly; that "in- and out-migration and mortality are not differential by the statuses we are considering." In other words, if they are studying patterns of school attendance, they assume that the people who move do not have particularly different patterns of school attendance than those who stay in the same geographic area (or, that the type of changes due to in- and outmigration cancel each other).

This is a very strong assumption and one that requires further exploration. There are some types of behavior that are not very much affected by migration patterns. For example, it is doubtful that the tuberculosis death rates for Massachusetts males between 1880 and 1930 would be greatly changed if we could adjust those rates for those who entered or left Massachusetts during that 50-year period (though the influx of foreigners before 1920, who probably had a higher tuberculosis-mortality rate than the native population, might have inflated the rates). Furthermore, the fact that the estimates of tuberculosis mortality rates are based on state-wide data rather than information from only one or two urban communities helps to minimize possible distortions due to migration.

The problem of estimates of life-course events being affected by selective migration is more serious when we are dealing with something like school attendance or labor-force participation in a single urban community. This is because young people in nineteenth-century America migrated to cities in order to work rather than to attend school. Therefore, we would expect that young people migrating to these cities would be less likely to attend school than their counterparts who grew up in that community. To test this proposition, we (Kaestle and Vinovskis, forthcoming) can look at the school-attendance patterns of children ages 13-19 in three Essex County urban areas (Lawrence, Lynn, and Salem) in 1880 to see whether those who were still living 


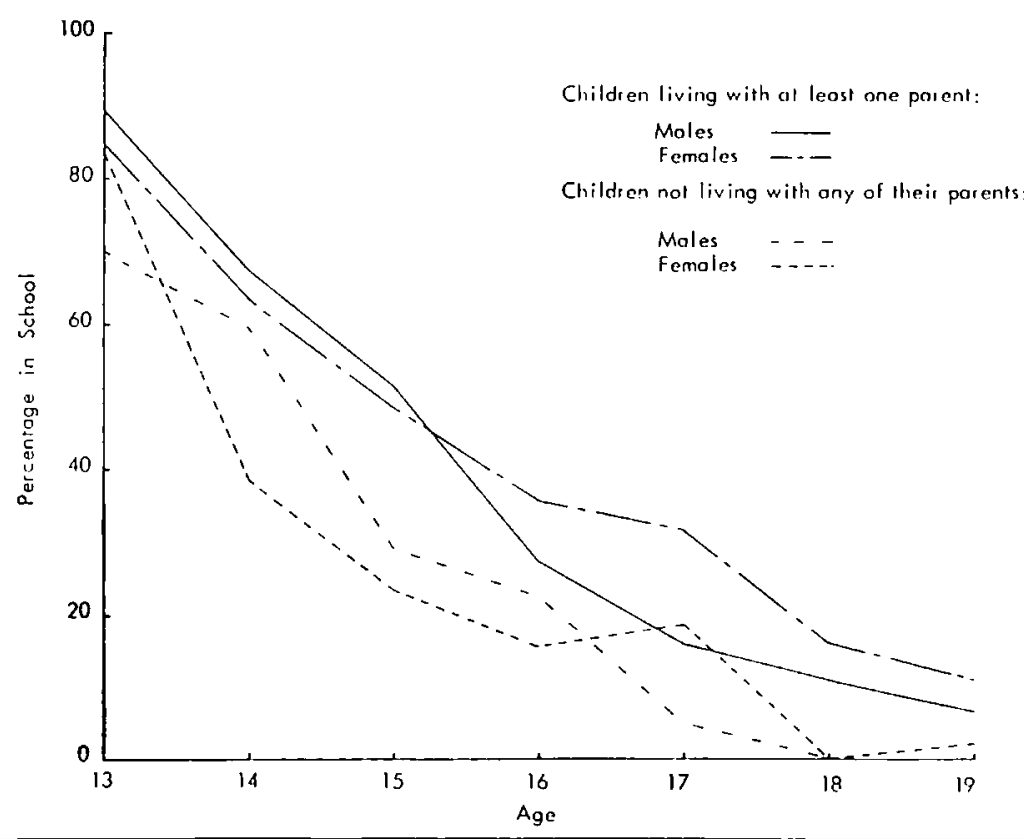

Figure 3. Percentage of Children Ages 13-19 Attending School in Eight Essex County Towns in 1880 .

with at least one of their parents were more apt to attend school than those who were boarders and lodgers (most of whom had probably migrated to those communities).

As we can see from Figure 3, children who were living with at least one parent were much more likely to be in school than those who were boarders and lodgers. Though this is an imperfect indication of the differences in the pattern of school attendance between migrants and nonmigrants, it does suggest that school attendance (as well as laborforce participation) was significantly affected by in- and out-migration. ${ }^{16}$ As a result, estimates of school attendance in rural areas exaggerate the extent of education received by children since many of those who did not continue their education left for urban areas to seek better employment opportunities. Conversely, the amount of education received by children growing up in urban areas would be underestimated due to the influx of teenage job seekers causing the statistics to appear to show lower school attendance rates for urban children. 
There are no simple ways of correcting for the biases introduced by selective migration, but at least family historians should acknowledge the problem and should be more cautious when they interpret their cross-sectional census data. There are some additional calculations which can be made that would help us to evaluate the extent and the direction of this type of bias. First, we can simply try to separate migrants from nonmigrants by using as crude an indicator as boarders and lodgers, and then calculate the rates for each group to see if there are major differences (as there were on the issue of school attendance and labor-force participation).

Another procedure, used effectively by Michael Katz (1975) in his study of family life in Hamilton, Ontario, is to compare the estimates of life-course experiences based on two cross-sectional censuses with those calculated for the individuals who remained in that community during that 10 -year period. Of course, this is still a very imprecise measure since the characteristics of those who remain in the community are usually very different than of those who remain in the community are usually very different than of those who leave it (Katz, 1975). Nevertheless, as long as one is aware of this bias and tries to adjust interpretations of the findings accordingly, the comparison of synthetic cohorts based on cross-sectional data with those who were actually present in both censuses does help us to see what biases have been introduced by our reliance on synthetic cohorts.

Some state censuses, such as the New York state census of 1855 , have information on how long an individual has lived in the community. This is a valuable piece of information which can be used to see the effects of migration on social phenomena such as school attendance. One cannot, of course, use these data directly to construct the life course of individuals by assuming that the behavior of those who have been in the community three years will be an indication of what will happen in another year to those who have lived in that community two years. ${ }^{17}$ This is due to the problem of selective outmigration. Some of those who have been in the community two years will leave within the next year and the characteristics of these migrants probably are not the same as those who will remain another year. In other words, the availability of state censuses which asked questions about the length of time individuals have been in a given community can be of great assistance for analysis of the life course, especially when compared to the data available from the manuscript federal censuses, but even these data cannot eliminate the biases introduced by selective migration. 
Finally, we can estimate the age-specific net migration in the communities under investigation in order to provide still another perspective on how migration might affect our estimates of life-course development. In a study of eight Essex County communities in 1860 and 1880, we (Kaestle and Vinovskis, forthcoming; Mason et al., forthcoming) calculated the population changes from 1860 to 1880 for each age category of the population. Then, using mortality rates from Massachusetts communities of the same size, we estimated the net migration for each of these towns. We discovered that, indeed, young people were moving into Lawrence, Lynn, and Salem in order to work, but many of them left after a few years. Consequently, any attempt to reconstruct the life experiences of individuals in those urban communities should adjust inferences from the cross-sectional data to account for the age-specific population flows in those cities.

Historians undoubtedly will and should continue to use the manuscript censuses to estimate life-course behavior. The fact that there are biases in such an approach is not the issue. Rather, the question is how we can estimate the extent and direction of the biases introduced in order to adjust our calculations to reflect more accurately the actual experiences of individuals and families. Some historians need to get away from their unwillingness to work with less than absolutely perfect data and procedures while others need to become more sensitive to the methodological and measurement problems associated with the use of nineteenth-century census data.

A good example of a conscious effort by a group of historians to use a life-course approach is the collaborative study of aspects of family transitions in eight Essex county (Massachusetts) towns in 1860 and 1880 (Hareven, forthcoming). Using a common data base from the manuscript federal censuses, an effort was made to analyse the lifecourse patterns of individuals in those communities as well as to place the findings within the broader context of existing demographic, economic, and sociological theories of family development.

Though there are many other substantive and methodological issues associated with the use of a life-course approach in studying family life, they cannot be covered in this essay. ${ }^{18}$ However, I will close with one final suggestion. Since the life-course perspective attempts to develop a more dynamic and interactive approach to the analysis of the past, it is essential that historians link the manuscript census data to other records. Calculation of life-course events at only 10-year 
intervals is much too crude to capture the continuities and discontinuities of behavior in the past.

One interesting and useful approach is to link vital records to census data. For example, Howard Chudacoff (forthcoming) studied the residential patterns of newly married couples by linking information from the Rhode Island marriage registers to the household data from the manuscript census. He discovered that a significant proportion of newlyweds in nineteenth-century Providence lived for a short time with one of their families - a finding which could not have been uncovered by reliance on either the marriage register or the manuscript census by itself.

This essay started by noting the bifurcation of approaches to family life in the past-one group of historians analyzed vital events using parish registers while another group analyzed household size and composition using the censuses. Though these two efforts have approached family life from a somewhat different perspective and have utilized different techniques of analysis, it is now time for them to be merged to provide a more balanced and dynamic analysis of family life in the past. The life-course approach suggests the need as well as the means for linking information about family processes with that of family size and composition within the context of historical changes in society as a whole. As a result, historians of the family should look forward to an even more productive and exciting future as we begin to link family events to historical events using a life-course perspective. Though the life course approach is not a panacea for the innumerable problems associated with studying the family in the past, it is a significant conceptual improvement that will facilitate further analysis.

\section{NOTES}

1. This essay will not attempt to discuss most of the substantive issues in the field of family history today-especially since there are already several good introductions to these issues elsewhere (Hareven, 1974, 1977; Hareven and Vinovskis, forthcoming; Laslett, 1972a; Vinovskis, 1974, 1976; Wrigley, 1969, 1977).

2. Since Allan Sharlin discusses the recent trends in historical demography in another essay in this volume, I will not pursue developments in this field in more detail.

3. The difference between a cross-sectional estimate at one point in time and one based on the development of an individual or a family over time can be illustrated from 
a study of antebellum Massachusetts school teachers (Bernard and Vinovskis, 1977). Though less than $2 \%$ of antebellum Massachusetts women ages 15 to 60 taught school, about $20 \%$ of them taught school at some point in their careers.

4. For a critique of Hill's generational approach as well as other approaches to the study of family life, see Elder (forthcoming).

5. Greven (1970) did organize his mortality data by cohorts rather than generations; unfortunately, his analysis of mortality was flawed because he improperly used estimates of cohort mortality to make inferences about mortality trends between the seventeenth and eighteenth centuries. For a critique of his analysis of mortality, see Vinovskis (1972).

6. Despite some of the methodological and substantive problems in Greven's analysis, it is still one of the best books in American historical demography today. For a detailed critique of it, see Vinovskis (1971).

7. The analysis of occupations from nineteenth-century censuses has been a major problem for historians and illustrates the difficulties of using historical data. For useful introductions to these problems, see Blumin (1968), Griffen (1972), and Hershberg et al. (1974).

8. For an example of a recent study using such data to develop an index of family income and consumption, see Sweet (1973).

9. Of the two different sets of weights used in these analyses, the ones for the consumption are probably the most reliable. It is very difficult to estimate the appropriate weights for wage earners because there is more variation in patterns of remuneration for workers than in consumption among household members in nineteenth-century America. For a more detailed discussion of these issues, see Kaestle and Vinovskis (forthcoming) and Mason et al. (forthcoming).

10. In fact, some of the early proponents of a family-cycle approach for historical analysis are now using a life-course perspective instead (Hareven, 1977).

11. For a discussion of the problems of using longitudinal studies as well as an inventory of those currently available, see Wall and Williams (1970).

12. One major criticism of historians is that we are too passive in acquiring data. Rather than being content with whatever documents and data happen to survive, we should be actively participating in the generation and collection of data that we are likely to need - in a manner similar to other social scientists. Historians should join some of the on-going panel studies of the family, not only to use their data, but also to suggest additional questions that could be incorporated which might be particularly useful to family historians. For example, some social historians might participate in James Morgan's and G. Duncan's (1977) valuable panel study of 5000 American families rather than sitting back for a few more years before discovering these data and then using them to analyze American family development from the late 1960s to the mid 1970s. If historians have a different perspective on the analysis of family life than most other social scientists, and I think some historians do, then it is essential that we should now collaborate with these other scholars rather than merely awaiting the data to be handed down to us at some future date.

13. Most historians have not used any longitudinal data from government, tradeunion, or business files. For an example of the richness of these types of data for an analysis of family life in the past, see the interesting study of Manchester workers by Hareven (1975).

14. On the use and misuse of nineteenth-century American census data, see Vinovskis (1977). 
15. The almost exclusive focus of individual-level census analyses on single urban communities has been rather unfortunate in at least two respects. First, very little effort has been made to design research projects to include different types of urban and industrial development for comparative purposes. Second, the reliance on only urban areas has made it impossible to separate analytically the effects of urban development from more general changes within that society. In other words, by not having any rural control areas in their analyses, for example, researchers cannot be certain whether the changes experienced by any group within a city over time are the result of the impact of urbanization on the lives or the consequence of more general developments within that society as a whole. For a more detailed discussion of this issue, see Vinovskis (1977).

16. Though not all unmarried boarders and lodgers in a community were migrants from elsewhere, most of them probably had come to the city to seek work. For a good discussion of the problem of boarders and lodgers in nineteenth-century America, see. Modell and Hareven (1973).

17. For an example of this problem in an otherwise excellent study, see Glasco (1975).

18. For a more extended critique of the way historians have studied family life in the past, see Hareven (1971), Vinovskis (1974), Hareven and Vinovskis (forthcoming), and Wrigley (1977).

\section{REFERENCES}

BER KNER, L. K. (1975) "The use and misuse of census data for the historical analysis of family structure." J. of Interdisciplinary History 4 (Spring): 721-738.

BERNARD, R. M. and M. A. VINOVSK IS (1977) "The female school teacher in antebellum America." J. of Social History 10 (Spring): 332-345.

BLUMIN, S. (1968) "The historical study of vertical mobility." Historical Methods Newsletter I (September): 1-13.

CHUDACOFF, H. (forthcoming) "The Non-Private Newlyweds: Familial Extension in the First Stage of the Family Cycle, Providence, Rhode Island, 1864-1865 and 18791880," in T. K. Hareven and M. A. Vinovskis (eds.) Demographic Processes and Family Organization in Nineteenth-Century American Society. Princeton: Princeton Univ. Press.

DUVALL, E. M. (1967) Family Development. Philadelphia: J. B. Lippincott.

ELDER, G. H., Jr. (forthcoming) "Family transitions and the life course," in T. K. Hareven (ed.) The Family Transition and the Life Course in Historical Perspective. New York: Academic Press. $165-190$.

- - (1974) Children of the Great Depression. Chicago: Univ. of Chicago Press.

FROST, W. H. (1940) "The age selection of mortality from tuberculosis in successive decades." Milbank Memorial Q. 1 (1940): 64.

GLASCO, L. (1975) "The life cycles and household structure of American ethnic groups: Irish, Germans, and native-born whites in Buffalo, New York, 1855." J. of Urban History l (May): 339-364. 
GREVEN, P. J., Jr. (1970) Four Generations: Population, Land, and Family in Colonial Andover, Massachusetts. Ithaca, NY: Cornell Univ. Press.

GRIFFEN, C. (1972) "Occupational mobility in nineteenth-century America: problems and possibilities." J. of Social History 5 (Spring): 310-330.

HAREVEN, T. K. [ed.] (forthcoming) Family Transitions in the Life Course in Historical Perspective. New York: Academic Press.

___(1977) "Family time and historical time." Daedalus 106 (Spring): 57-70.

_-_ (1975) "Family time and industrial time." J. of Urban History I (May): 365-389. (1974) "The family as process: the historical study of the family cycle." J. of Social History 7 (1974): 322-329.

_- (1971) "The history of the family as an interdisciplinary field." J. of Interdisciplinary History 2 (Autumn): 399-414.

- - and M. A. VINOVSKIS (forthcoming) "Introduction," in T. K. Hareven and

M. A. Vinovskis (eds.) Demographic Processes and Family Organization in Nineteenth-Century American Society. Princeton: Princeton Univ. Press.

HENRY, L. (1956) Anciennes families genevoises. Etude demographique XVI-XXe siecles. Paris: Processes Universitaires de France, Travaux et Documents de l'Institute National d'Etudes Demographiques, Cahier 26.

HERSHBERG, T., M. KATZ, S. BLUMIN, L. GLASCO, and C. GRIFFEN (1974) "Occupation and ethnicity in five nineteenth-century cities: collaborative inquiry." Historical Methods Newsletter 7 (June): 174-216.

HILL, R. (1964) "Methodological issues in family development research." Family Process 3 (March): 186-206.

HILL, R., N. FOOTE, J. ALDOUS, R. CARLSON, and R. MACDONALD (1970) Family Development in Three Generations: a Longitudinal Study of Changing Family Patterns of Planning and Achievement. Cambridge, MA: Schenkman.

KAESTLE, C. F. and M. A. VINOVSKIS (forthcoming) "From fireside to factory: school entry and school leaving in nineteenth-century Massachusetts," in T. K. Hareven (ed.) Family Transitions and the Life Course in Historical Perspective. New York: Academic Press.

KATZ, M. B. (1975) The People of Hamilton, Canada West: Family and Class in a Mid-Nineteenth-Century City. Cambridge: Harvard Univ. Press.

LASLETT, P. (1977) "Characteristics of the western family considered over time." J. of Family History 2 (Summer): 89-115.

-_- (ed.) with the assistance of RICHARD WELL (1972a) Household and Family in Past Time. Cambridge, England: Cambridge Univ. Press.

LASLETT, P. (1972b) "Mean household size in England since the sixteenth century," pp. 125-158 in P. Laslett (ed.) Household and Family in Past Time. Cambridge, England: Cambridge Univ. Press.

LEVY, M. J., Jr. (1965) "Aspects of the analysis of family structure," pp. 1-63 in A. J. Coale, L. A. Fallers, M. J. Levy, Jr., D. M. Schneider, and S. S. Tomkins (eds.) Aspects of the Analysis of Family Structure. Princeton: Princeton Univ. Press.

MASON, K., M. A. VINOVSKIS, and T. K. HAREVEN (forthcoming) "Determinants of women's labor force participation in late nineteenth-century America," in T. K. Hareven (ed.) Family Transition and the Life Course in Historical Perspective. New York: Academic Press.

MODELL, J. (1975) "Levels of change over time." Historical Methods Newsletter 8 (September): 116-127. 
and T. K. HAREVEN (1973) "Urbanization and the malleable household: an examination of boarding and lodging in American families." J. of Marriage and the Family 35 (August): 467-479.

-- , F. FURSTENBURG, and T. HERSHBERG (1976) "Social change and transitions to adulthood in historical perspective." J. of Family History 1 (Autumn): 7-32. MORGAN, J. N. and GREG DUNCAN [eds.] (1977) Five Thousand American Families:

Patterns of Economic Progress. Ann Arbor, MI: Institute for Social Research.

RILEY, M. W., M. E. JOHNSON, and A. FONER [eds.] (1972) Aging and Society: a Sociology of Age Stratification. New York: Russell Sage.

RODGERS, R. (1962) Improvements in the Construction and Analysis of Family Life Cycle Categories. Kalamazoo: Western Michigan Univ.

RYDER, N. B. (1965) "The cohort as a concept in the study of social change." Amer. Soc. Rev. 30 (December): 843-861.

SKOLNICK, A. (1975) "The family revisited: themes in recent social science research." J. of Interdisciplinary History 4 (Spring): 703-719.

SWEET, J. A. (1973) Women in the Labor Force. New York: Seminar Press.

VINOVSKIS, M. A. (1977) "Problems and opportunities in the use of individual level and aggregate level census data." Presented at the Conference on Quantification and Methods in Social Science Research. Cologne, Germany (August).

- - (1976) Demographic History and the World Population Crisis. Worcester, MA: Clark Univ. Press.

- (1974) "The field of early American family history: a methodological critique."

The Family in Historical Perspective 7 (Winter): 2-8.

___ (1972) "Mortality rates and trends in Massachusetts before 1860." J. of Economic History 32 (March): 184-213.

- (1971) "American historical demography: a review essay." Historical Methods Newsletter 4 (September): 141-148.

WALL, W. D. and H. L. WILLIAMS (1970) Longitudinal Studies and the Social Sciences. London: Heinemann.

WRIGLEY, E. A. (1977) "Reflections on the history of the family." Daedalus 106 (Spring): 71-85.

(1969) Population and History. New York: McGraw-Hill. 